\title{
COMMENTARY
}

\section{A comment on the influence of dingoes on the Australian sheep flock}

DM Forsyth, ${ }^{a^{*}}$ AP Woolnough, ${ }^{b}$ DG Nimmo, ${ }^{c}$ EG Ritchie, ${ }^{c}$ M Kennedy, ${ }^{d}$ A Pople and I Watson ${ }^{\mathrm{e}}$

Allen and West recently proposed that dingoes (Canis dingo, including hybrids with feral dogs C. lupus familiaris) are a critical causal factor in the decline of Australia's sheep (Ovis aries) flock and implied that dingoes would cause the rangeland sheep industry to disappear within 30-40 years. ${ }^{1}$ We agree that dingo predation can reduce the profitability of affected sheep properties and has important negative social effect on rural communities, and that exclusion fences and a range of lethal control methods are options for reducing those negative effects. However, we argue that the importance of dingoes as a cause of the decline in Australia's sheep flock has been overstated.

The Australian sheep flock peaked at 180 million in 1970, declined and then increased to 170 million in 1990, but has since declined sharply to 74 million in 2011 (Figure 1a). Sheep flocks in the other major southern hemisphere sheep-growing nations have undergone similar long-term declines. New Zealand's sheep flock peaked at 70 million in 1982, but has since steadily declined to 31 million in 2011 (Figure 1b). Argentina's sheep flock has steadily declined from 50 million in 1961 to 16 million in 2011 (Figure 1c). South Africa's sheep flock has declined from 40 million in 1966 to 24 million in 2011 (Figure 1d). The USA's sheep flock has also been in long-term decline, from a peak of 56 million in 1945 to just 5.5 million in 2011..$^{2,3}$ Mammalian predators of sheep are present in Argentina, South Africa and USA, ${ }^{4}$ but not in New Zealand.

The similar rate of decline in the sheep flocks of Australia and other sheep-producing nations suggests broader commodity issues influence the industry in Australia rather than just dingo predation. The five detailed reviews published on Australia's sheep industry since $1990^{5-9}$ all attribute Australia's declining sheep flock to a longterm decline in the real price paid for wool compared with other textiles, and to the high cost of growing and processing wool, reducing the profitability of wool growing relative to other agricultural products. A similar conclusion was reached for the cause of declining sheep flocks in New Zealand ${ }^{10}$ and the USA., ${ }^{2,4}$ Global demand for wool has been in long-term decline because it cannot compete on price or volume with synthetics and cotton. ${ }^{7}$ Hence,

*Corresponding author.

${ }^{a}$ Arthur Rylah Institute for Environmental Research, Department of Environment and Primary Industries, Heidelberg, Victoria 3084, Australia; dave.forsyth@depi.vic.gov.au biosecurity Division, Department of Environment and Primary Industries, East Melbourne, Victoria, Australia

${ }^{c}$ Centre for Integrative Ecology and School of Life and Environmental Sciences, Deakin University, Melbourne, Victoria, Australia

${ }^{\mathrm{d}}$ Department of Agriculture and Food, Western Australia, South Perth, Western Australia, Australia

envasive Plant and Animal Science, Biosecurity Queensland, Department of

Agriculture, Fisheries and Forestry, Brisbane, Queensland, Australia

${ }^{\mathrm{f}} \mathrm{CSIRO}$ Ecosystem Sciences, Aitkenvale, Queensland, Australia

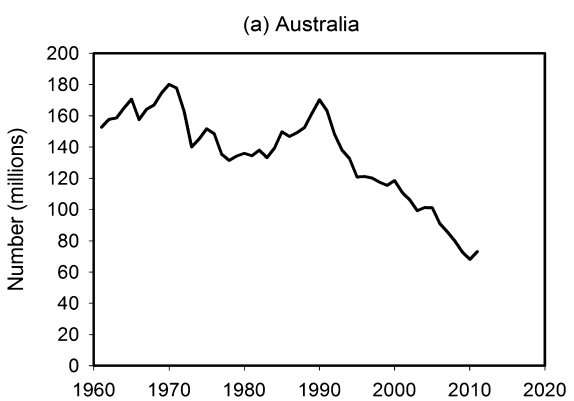

(b) New Zealand
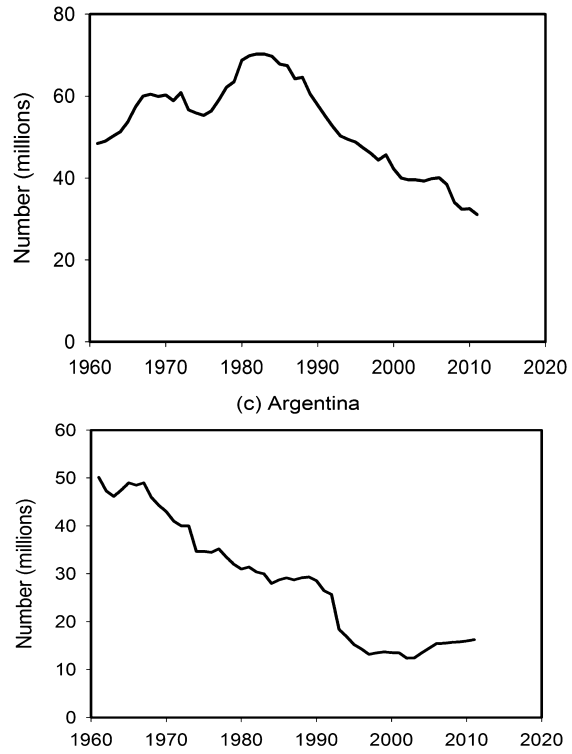

(d) South Africa

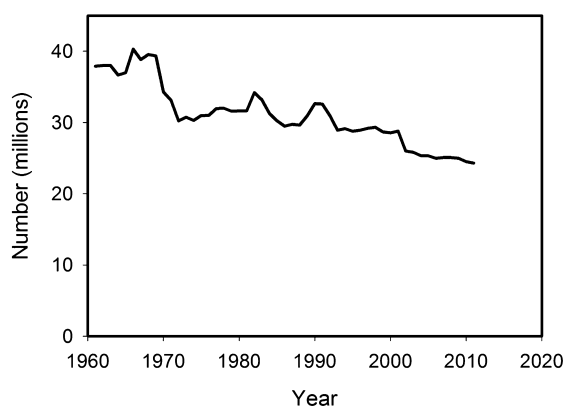

Figure 1. National sheep flock sizes in (a) Australia, (b) New Zealand, (c) Argentina and (d) South Africa, 1961-2011 (data source: Food and Agriculture Organization of the United Nations, available at http:// faostat.fao.org/). 


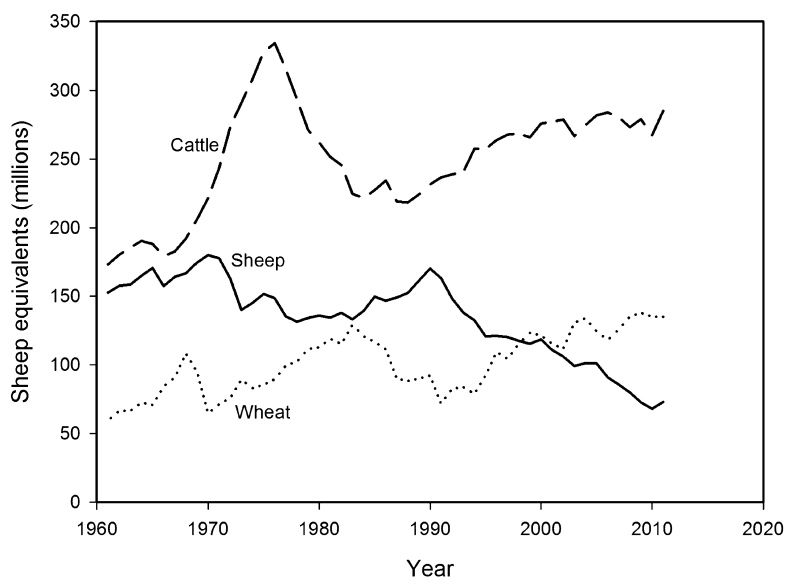

Figure 2. Trends in Australian cattle, sheep and wheat 1961-2011. Cattle numbers assume that 1 large stock unit is equivalent to 10 sheep and wheat is the product of the hectares in production multiplied by 10 sheep per ha ${ }^{9}$ (data source: Food and Agriculture Organization of the United Nations, available at http://faostat.fao.org/).

wool prices paid to farmers have declined substantially in real terms since $1950^{2,5,7,11,12}$ and particularly after its reserve price scheme was phased out in the late 1980s. s,7 $^{5,7}$ One review noted the importance of dingo predation on sheep in Australia during the $1800 \mathrm{~s},{ }^{7}$ but none of the reviews mentioned dingo predation as a cause of the post1990 decline in Australia's sheep flock.

Farmers can be expected to maximise the profitability of their businesses. ${ }^{6}$ Hence, the sustained decline in the profitability of sheep products, particularly wool, relative to beef, dairy and wheat has resulted in large increases in Australia's cattle population and the area under wheat production ${ }^{6,9}$ (Figure 2). Sheep numbers have declined in all regions of Australia, but since 1990 have declined most in the wheat-sheep zone where farmers have reduced their sheep flocks and increased their wheat acreages. ${ }^{6}$ The inland pastoral rangelands are mostly unsuitable for growing wheat and wool growers there have reduced sheep flocks and increased cattle numbers (e.g. western New South Wales and Queensland). ${ }^{6,13} \mathrm{Com}$ mercial harvesting of feral goats (Capra hircus) has become increasingly important for producers/graziers in these areas (Figure 3), with some actively reducing sheep densities to increase their feral goat harvests. ${ }^{14}$ This has occurred because the price of wool has declined since 1990, but the price paid per feral goat has increased substantially ${ }^{14}$ and has been matched by an increase in the abundance of feral goats in some traditional sheep rangelands. ${ }^{15}$

The management of sheep predators such as dingoes is a cost of production, and decisions about their management will depend on the perceived benefit versus cost. We believe that the reduced investment in dingo management highlighted by Allen and West ${ }^{1}$ is a symptom rather than a cause of the declining profitability of sheep farming in Australia's rangelands. ${ }^{4}$ If the benefit of dingo management exceeded the cost, then the economically rational decision would be to do it.

\section{Acknowledgments}

This contribution was funded by the Biosecurity Division, Department of Environment and Primary Industries. Aaron

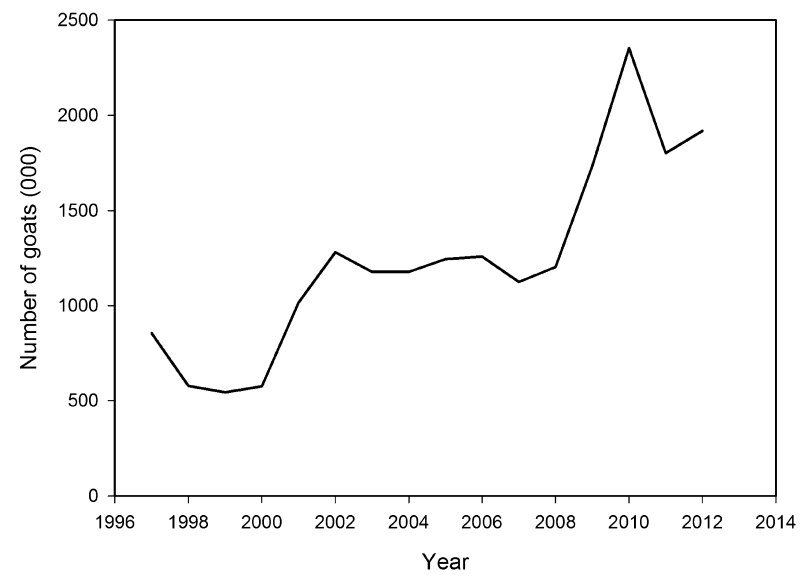

Figure 3. Number of goats slaughtered in Australia or exported live from Australia during the 1997-2012 calendar years. Feral goats comprise $90 \%$ of the number slaughtered and the majority of these come from pastoral rangelands. ${ }^{15}$ Data were unavailable prior to 1997 (data source: Meat \& Livestock Australia, available at http://www.mla.com.au).

Meikle and Alan Robley made valuable comments on the draft manuscript.

\section{References}

1. Allen $B L$, West P. Influence of dingoes on sheep distribution in Australia. Aust Vet J 2013;91:261-267.

2. Jones KG. Trends in the u.s. sheep industry. United States Department of Agriculture, Economic Research Service, 2004.

3. FAOSTAT. Food and Agriculture Organization of the United Nations statistical databases. http://faostat.fao.org/. Accessed January 2014.

4. Berger KM. Carnivore-livestock conflicts: effects of subsidized predator control and economic correlates on the sheep industry. Conserv Biol 2006;20:751-761.

5. Australian Wool Industry Future Directions Task Force. Diversity and innovation for australian wool. AWI Future Directions Task Force, Adelaide, 1999.

6. Martin P, King J, Shafron W. Australian wool industry 2004. Australian Wool Innovation Limited, Canberra, 2004.

7. Henzell T. Australian agriculture: its history and challenges. CSIRO Publishing, Collingwood, 2007.

8. Curtis, K. Wool desk september 2009 'changes in the Australian sheep industry'. Department of Agriculture and Food, Western Australia, 2009.

9. Rowe JB. The Australian sheep industry: undergoing transformation. Anim Prod Sci 2010;50:991-997.

10. Davison R. Sheep and beef outlook drivers. http://www.beeflambnz.com/ Documents/Information/Sheep\%20and\%20beef\%20outlook\%20drivers.pdf.

Accessed January 2014.

11. Australian Bureau of Agricultural and Resource Economics and Sciences. Agricultural commodity statistics 2013. ABARES, Canberra, 2013.

12. Beef + Lamb New Zealand. Compendium of New Zealand farm facts. 37 th edn. Beef + Lamb New Zealand Economic Service, Wellington, 2013.

13. Gutteridge MC, Stone GS, Hall WB et al. National rangelands theme. Project 1.5: intensity of land use. Final report. Queensland Department of Natural Resources and Mines, Brisbane, 2001.

14. Forsyth DM, Parkes JP, Woolnough AP et al. Environmental and economic factors determine the number of feral goats commercially harvested in Western Australia. J Appl Ecol 2009;46:101-109.

15. Pople T, Froese J. Distribution, abundance and harvesting of feral goats in the Australian rangelands 1984-2011. Department of Employment, Economic Development and Innovation, Brisbane, 2012. 